\title{
Verification of educational effect for innovation practice on electrical technology
}

DOI: $10.46932 / \mathrm{sfjdv2n5-095}$

Received in: Oct 1st, 2021

Accepted in: Dec 30th, 2021

\author{
Takashi Matsumoto \\ Professor of the Department of Creative Technology Engineering, \\ National Institute of Technology,Anan College. \\ His expertise covers environmental electromagnetic engineering and educational engineering \\ 265 Aoki, Minobayashi-cho, Anan-shi, Tokushima, 774-0017, JAPAN \\ E-mail: matumoto@anan-nct.ac.jp
}

Minoru Komatsu

Associate Professor of the Department of Creative Technology Engineering, National Institute of Technology, Anan College.

His expertise covers electromagnetic engineering and educational engineering.

\begin{abstract}
There is a need to develop human resources who can play an active role in the intense competition of international society. We created a practice in which students acquire fundamental competency by working on electrical technologies in a virtual company. By starting a mock company on their own, the first aim for students is to learn basic company management, the second aim is for them to acquire the skills required as a member of society, and the third aim is for them to gain knowledge about the latest technology in the field of electrical technology. Students learn about company management systems through participation in administrative procedures such as manufacturing, sales, personnel and accounting practices. In order to establish a company related to electrical technology, it is necessary to analyze cutting-edge technologies in each field (electric power, electronics, robots, AI, IoT, entertainment, etc.), and second-year students can begin their investigation, which is the same as learning about research backgrounds previously conducted primarily in graduation research. The mock company requires a collection of capital and performs all costs related to the business using a virtual currency called ANET Coins. Teachers make investments as shareholders or request proposals from the students' company as virtual currency holders. All information related to this practice is managed on the LMS (Learning Management System). This practice is a chance to recognize and act in various situations and will become an opportunity for reflection. The results of the student surveys regarding the improvement of competency, which working adults are required to have, showed that this practice is more effective than any prior experiences. In this paper, we show the contents of the innovation practice on electrical technologies and describe the verification of the educational effect from student surveys. This practice can be widely applied in the field of Education.
\end{abstract}

Keywords: virtual company, electrical technologies, practice, virtual currency, Learning Management System, Standards: 2, 3, 7, 8 . 


\section{INTRODUCTION}

Currently, higher education institutions are required to develop human resources who can play an active role in a modern society where international competition is intensifying. Therefore, in addition to the knowledge and skills of the past, it is necessary to have competencies such as basic skills for working adults [Ministry of Economy, 2018], bachelor's ability [Education, 2012], and cross-disciplinary abilities [Technology, 2017]. In addition, from the viewpoint of new Education that fosters the ability to play an active role in a global society, the OECD's international learning achievement test called PISA is based on the investigation of emotional abilities at PISA2018 and meta-competency at PISA2021 [Research, 2019]. According to the survey in PISA, the age of competency evaluation is progressing, and efforts to develop competency through active learning in elementary and (American Psychological Association, 2018) junior high schools have begun [Shigeo Kawamura, 2016]. It is important in the education field to create more opportunities to acquire the necessary skills to create useful human resources in society [Sadayuki Shimoda, 2016]. In order to develop such competency, each school has been promoting the active learning of regular lectures and has introduced problem-solving learning and student-participation learning.

The authors show that if students can experience competencies that can be acquired for the first time by experiencing everything from job hunting to work, we will improve our students' abilities if we can experience them in our studies at technical colleges. We have created an electrical technology innovation practice (hereafter, this practice) in which students work as virtual members of society. In April 2018, it was introduced as one theme of electrical and electronic engineering experiments in the electrical course [Minoru Komatsu, 2019].

In this paper, we construct an innovation practice for electrical technology that is conscious of working people, shows the contents and state of activities, and verifies the effectiveness of the practice. This practice is for the second to fifth-year students of the electrical course. Therefore, we have established a company based on electrical Technology, but since various applications are possible, it is a practical training that can be adopted widely not only in a technical college but also from high school to university. In addition, there will basically be one teacher in charge of this training.

\section{PRACTICE PURPOSE}

In this practice of starting a mock company, the first thing students learn is basic company management, secondly, to acquire the skills required as a member of society, and thirdly to become familiar with cutting-edge electrical Technology. The purpose is to make connections that exceed their grade-level in the course, respectively, in the fourth grade. 
By being involved in company management, students are able to learn from experience how to carry out administrative procedures such as manufacturing, sales, personnel, and accounting, and acquire basic skills required for working people from various social experiences, including ordering from other companies and conducting personnel exchange.

This practice will be a chance to recognize and act in various situations, and it will be an opportunity for students to reflect on their experiences. Failure in this practice is not a problem at all, and the experience of failure is connected to what comes next, as well as self-reflection and the growth cycle by PDCA, which is originally required and all of which are established by students themselves.

In this practice, students will also learn about financial Education by the introduction of an oncampus virtual currency (ANET coins) and by conducting all exchanges (salary, purchase costs, facility management expenses, etc.) in this virtual currency. This virtual currency exists only on the Cloud Education Support System. It is a historical credit record of the exchange of virtual currency between the teacher and the student. The introduction of virtual currencies not only enables more realistic transactions but also increases student motivation.

In order to establish a company related to electrical technology, it is necessary to analyze the cutting-edge technologies of each field (electric power, electronics, robots, AI, IoT, entertainment), and second-year students can begin their investigations of the research background that was previously conducted only in graduation research. Figure 1 shows the innovation practice of electrical Technology. In this practice, students from each grade make up one company, so that students can connect not only in class but also across grade levels. In the past, there has been a connection in the class, but the connection beyond the school year has been thin, so this practice includes elements of club activities, which are extracurricular activities.

Figure 1. Overview of innovation practice on electrical Technology

\begin{tabular}{|c|c|c|c|c|}
\hline \multicolumn{5}{|c|}{$\begin{array}{l}\text { Innovation Practice on Electrical Technologies } \\
\text { For Anan Colleqe }\end{array}$} \\
\hline 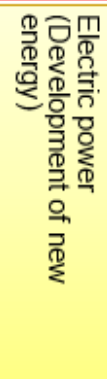 & 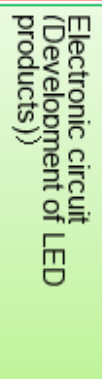 & 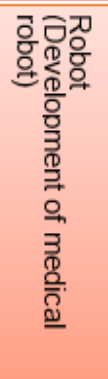 & 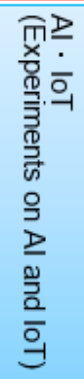 & 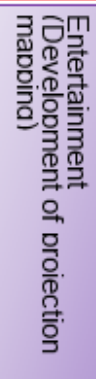 \\
\hline \multicolumn{5}{|c|}{$\begin{array}{l}\text { Contents of work } \\
\text { 1. Proposal for work useful for society } \\
\text { 2. Development of new products } \\
\text { 3. Entrance examination and college festival } \\
\text { 4. Research assistance } \\
\text { 5. Experiment preparation } \\
\text { 6. Teaching assistant } \quad \text { etc. }\end{array}$} \\
\hline
\end{tabular}




\section{PRACTICE CONTENTS}

This practice is put forth as one of the electrical and electronic engineering experiments for thirdgrade students as well as from the second to fourth grades. Electrical and electronic engineering experiments are conducted on 8 to 12 themes in each grade and will be incorporated as an additional theme. The first group is held every other week in which the second group conducts this practice on the day for experimenting with other themes. Since the experimental date is different for each grade and there is no opportunity for the entire company to gather, we set up an electrical and electronic engineering experiment supplement each week on a timetable and use it for internal meetings. The fifth-grade students are cryptocurrency holders who work on creative engineering exercises, graduation research, and invest in companies.

As for the start-up method, the teacher selects ten presidents from amongst the fourth-grade students after an examination of their business plans, and fourth-grade students conduct interviews with other students and determine the place of employment for all fourth-grade students. It is possible for anyone to start an independent business in the middle of the year. Students who wish to become independent can submit a new business plan and start a business if students can acquire ANET Coins for the necessary funds to be included in the business plan through the ANET capital-acquisition presentation. Second- and third-year students go job hunting among the companies the fourth-year students started, deciding where to find a job. After their employment, students can set up an independent company after a certain period.

As a company organization, about ten students can be hired with additional people as necessary. The company shall start by raising capital and performing all expenses related to the business in virtual currency (ANET Coins). The evaluation of this practice shall be based on the business report submitted by each individual, and the evaluation of the first theme of the experiment.

All information related to this practice, such as work requests and report submissions, shall be provided using the LMS cloud education support system. Figure 2 shows the LMS.

As a cryptocurrency holder, the faculty will make a business request after receiving investment or a student's proposal. Teachers and technical staff may participate as counselors, and if students consult with each other, students will pay a consultation fee and carry out the consultation.

The company's business hours shall be only four hours per week (3 hours for experiments and 1 hour for supplementary lectures) and will be held every other week in relation to other experimental themes. The one-hour experimental course, which is common to students in all grades, will be used for internal meetings, etc., and the purpose of the following tasks and the reports from everyone will be carried out to improve the quality of the company's business. 
Figure 2. LMS (Cloud Education Support System)

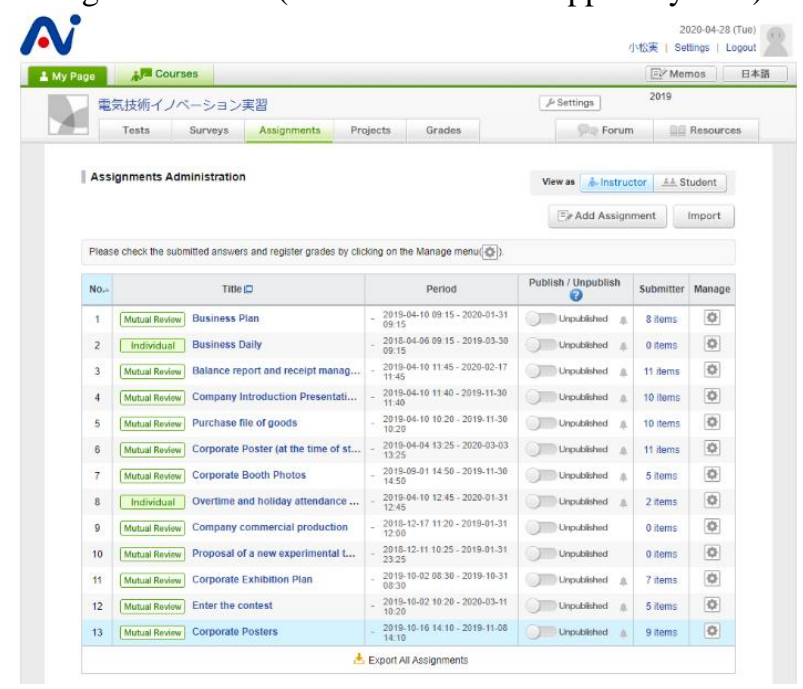

\section{ACTIVITIES}

Figure 3 shows the company briefing for third-year students conducted in April. Five companies held joint-briefings, and the fourth-year students prepared the company introduction in advance with projectors and handouts and explained in detail to the third-year students. The fourth-years who explained their companies began with the president's self-introduction and then the appeal of the company from various perspectives, such as the corporate atmosphere, corporate philosophy, corporate culture, and what kind of work students would like to do based on the theme that is the axis. The third-year students who were job hunting took part in briefings with nervous faces and took notes and chose the company seriously. In the interview, the fourth-year students prepared to ask questions on their own and consulted with them about what kind of employees the company wanted. Third-year students were observed to be so nervous that their hands which held resumes trembled. Figure 4 shows the interview at the employment examinations.

Figure 3. Picture of the company briefing

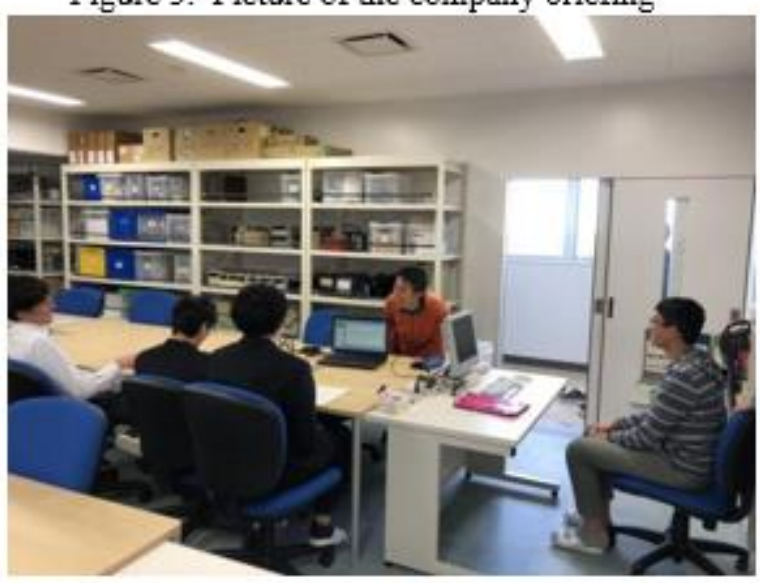

Figure 4. Picture of the interview

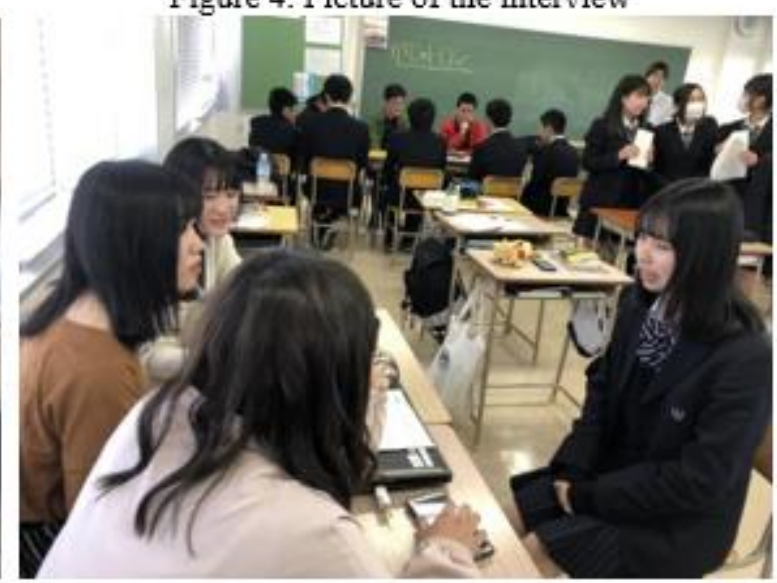


Figure 5. Picture of the flow of planning a project and the meeting for the entire company
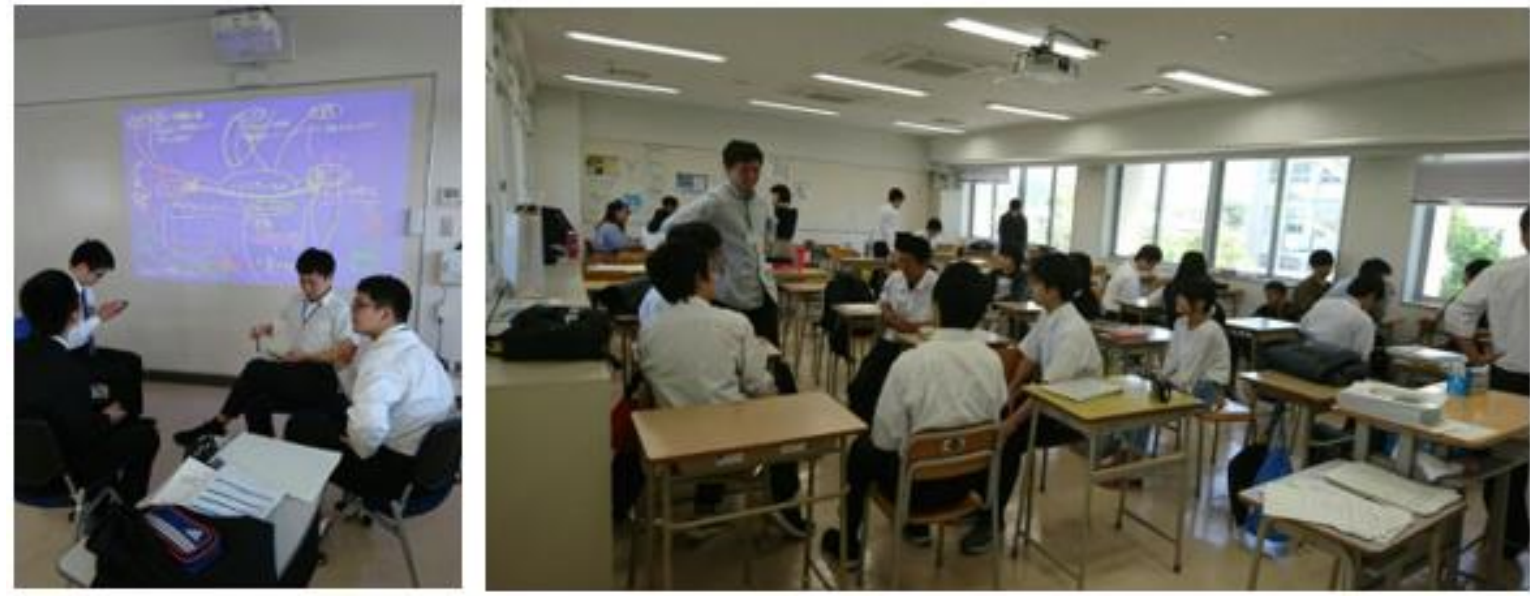

Figure 6. Picture of an e-sports tournament as an activity

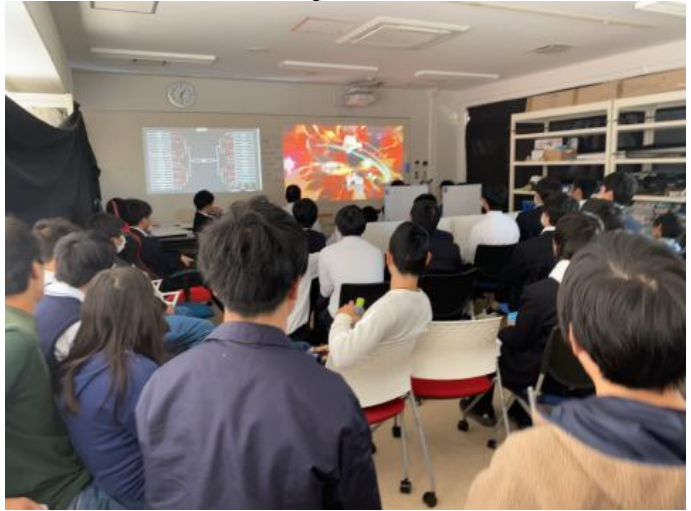

Each task is carried out by planning out the flow of a project, discussing it at an internal meeting, and then working on it. After it is over, a reflection meeting is held. Figure 5 shows the planning of the flow of a project and the meeting of the entire company. Figure 6 shows an e-sports tournament as an activity. E-sports is an event in which the event management company operates the tournament and participates in a variety of students.

\section{QUESTIONNARIRE RESULTS}

Questions 1 and 2 were directed at students in the second and third years who were looking for a job. Questions 3 and 4 focused on third and fourth-year students.

(1) Were you nervous about the interview?

(2) Was this company interview experience meaningful?

(3) What kind of character of student could you grasp at the interview?

(4) After you experienced being an interviewer, has your attitude changed in the future? 
Choose an answer from the following five: 5: Many, 4: Little, 3: Neither, 2: Not so much, 1: Not at all. Figure 7 shows the results of a questionnaire in job hunting. As shown in Figure 7, 5 and 4 answers to each question were more than $80 \%$, and the results were valid.

Figure 7. Results of a questionnaire in job hunting

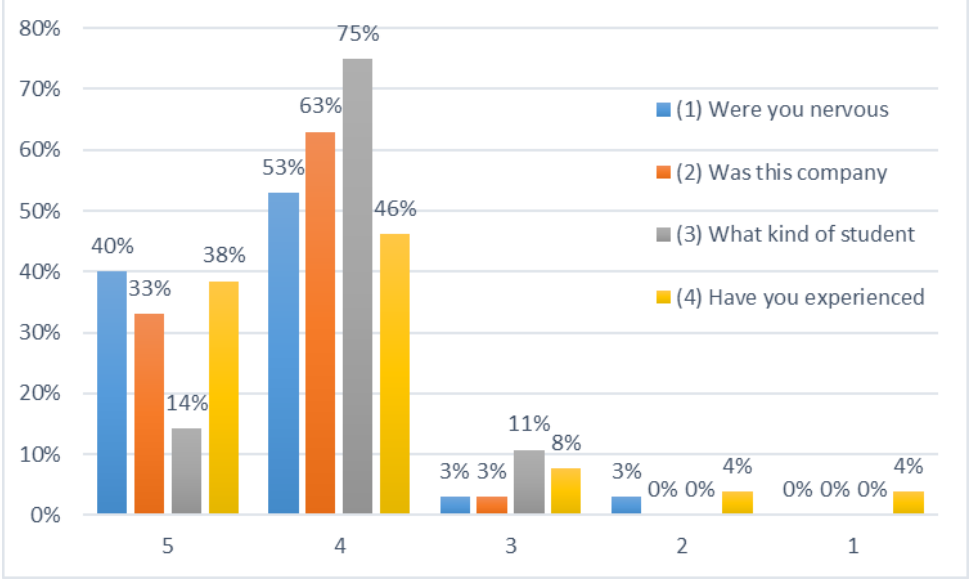

Figure 8. Results of communication skills, problem detection ability, and independence

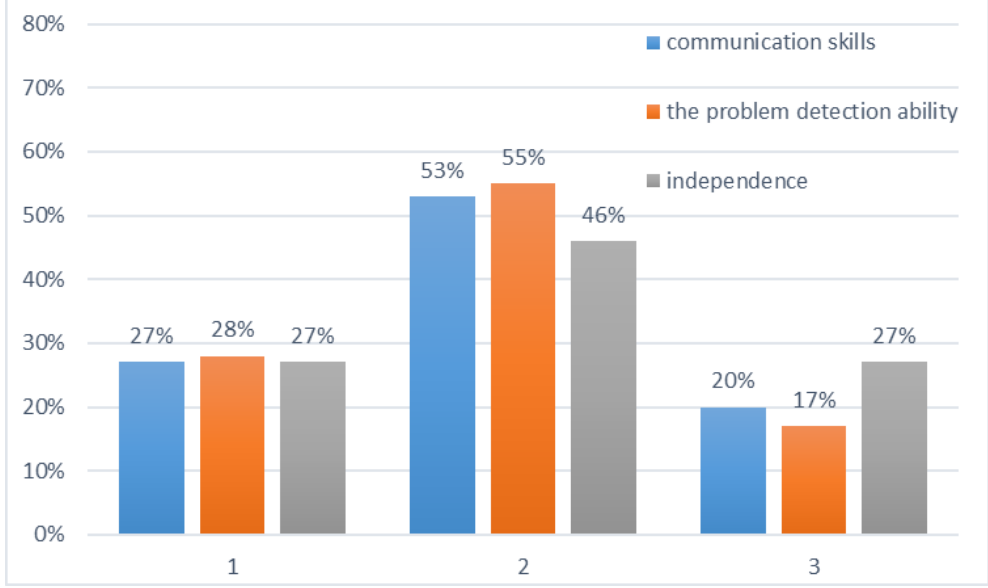

Figure 8 shows the results of communication skills, problem-solving skills, and subjectivity. The results of the survey show that between $70 \%$ and $90 \%$ of respondents in 1 and 2 have helped to improve their skills.

This is a question about communication skills.

1. You can express your opinion.

2. Actively exchange opinions.

3. You can communicate your opinion, convincingly.

This is a question about the ability of problem detection.

1. You can mention yourself or your group's challenges.

2. You can set up specific action scans that you or your group should take.

3. It is possible to determine effective action proposals to achieve the issues that you and your group should achieve. 
This is a question about independence.

1. You understand the roles and actions required of you.

2. You understand the content and meaning of the roles and actions required of you.

3. You can think for yourself about your roles and actions.

These surveys are in the first year, and the effectiveness of this practice can be verified by continuing the investigation. From the next year, we plan to devise a way to confirm the growth of competency due to differences in the way of engaging in practical training.

\section{CONCLUSION}

In this paper, we develop and describe the contents of an electrical technology innovation practice in which students become virtual members of society. Students followed the basic rules of working as members of society and worked with a sense of motivation. In this practice, the introduction of cryptocurrency was very effective, and we focused on sales and development so as not to bankrupt the companies.

This practice is conducted in the second year, and although the first year and second year have not been compared, it is seen as beneficial for the student's growth from various viewpoints. There are new proposals from students one after another because there is an opportunity to do what students want to do in this practice. Students often try new things without fear of failure. Guidance for passive students is also progressing, and there is an initiative that is conscious of competency from the lower grades, such as changing jobs and holding self-development seminars.

In the future, we plan to verify the effect every year and continue to evolve this practice with a focus on further competency development by incorporating new collaboration between companies. We hope that students who have experienced this practice will bring about new innovations in society. 


\section{REFERENCES}

Industrial Human Resources Policy Office, Ministry of Economy, Trade and Industry. Japan (2018). On the Basic Ability of Working People in the 100-Year Age of Life. Retrieved December 12, 2019, from http://www.meti.go.jp/committee/kenkyukai/sansei/jinzairyoku/jinzaizou_wg/pdf/007_06_00.pdf

Central Council for Education, Ministry of Education. Japan (2012). To build a new future toward a qualitative shift in university education. Retrieved December 12, 2019, from http://www.mext.go.jp /component/b_menu/shingi/toushin /__icsFiles/afieldfile/2012/10/04/1325048_1.pdf

National Institute of Technology. Japan (2017). Model Core Curriculum. Retrieved December 13, 2019, from https://www.kosen-k.go.jp/Portals/0/MCC/mcc2017all.pdf

National Insutitute for Educational Policy Research. Japan (2019). Retrieved December 12, 2019, from http://www.nier.go.jp/kokusai/pisa/index.html

Shigeo Kawamura, Yuka Musashi. (2016). A Study on Installing Active Learning Style in the Elementary School - In Comparison with the Current Class Structure -, Japan Society for Educational Counseling, Vol.7, No.1, 1-9

Sadayuki Shimoda, Kazuya Kanda, Kazuaki Shiraishi, Takayuki Tamai, Taiji Tsuboi, Yukito Kobayashi. (2016, September 7). Quality Assurance for the Model Core Curriculum in National Institute of Technology:part 7, Japanese Society for Engineering Education, 3C12, 448-449

Minoru Komatsu, Takashi Matsumoto. (2019, November 1). Construction of Innovation Practice on Electrical Technology for Working Persons. IEEJ Transactions on Fundamentals and Materials. Vol.139. No.11. 492-497 